\title{
LOGARITHMIC CONVEXITY, FIRST ORDER DIFFERENTIAL INEQUALITIES AND SOME APPLICATIONS $\left(^{(}\right)$
}

\author{
BY \\ HOWARD ALLEN LEVINE
}

\begin{abstract}
Let, for $t \in[0, T)(T<\infty), D(t)$ be a dense linear subspace of a Hilbert space $H$, and let $M(t)$ and $N(t)$ be linear operators (possibly unbounded) mapping $D(t)$ into $H$. Let $f:[0, T) \times H \rightarrow H$. We give sufficient conditions on $M, N$ and $f$ in order to insure uniqueness and stability of solutions to
\end{abstract}

$$
M(t) d u / d t=N(t) u+f(t, u), \quad u(0) \text { given. }
$$

This problem is not in general well posed in the sense of Hadamard. We cite some examples of (1) from the literature. We also give some examples of the problem

$$
M(t) \frac{d^{2} u}{d t^{2}}=N(t) u+f\left(t, u, \frac{d u}{d t}\right), \quad u(0), \frac{d u}{d t}(0) \text { prescribed, }
$$

for which questions of uniqueness and stability were discussed in a previous paper.

I. Introduction. In an earlier paper [10], the author presented a number of theorems concerning the questions of uniqueness and stability of the null solution to the Cauchy problem for abstract differential inequalities of the form

$$
\left\|M(t) \frac{d^{2} w}{d t^{2}}-N(t) w\right\| \leqq \beta\left(t, w, \frac{d w}{d t}\right)
$$

or

$$
\left\|\frac{d}{d t}\left(M(t) \frac{d w}{d t}\right)-N(t) w\right\| \leqq \beta\left(t, w, \frac{d w}{d t}\right)
$$

where

$$
\begin{aligned}
\beta^{2}\left(t, w, \frac{d w}{d t}\right)= & k_{1}|(w, M(t) w)|+k_{2} \int_{0}^{t}|(w, M(t) w)| d s \\
& +k_{3}\left|\left(\frac{d w}{d t}, M(t) \frac{d w}{d t}\right)\right|+k_{4} \int_{0}^{t}\left|\left(\frac{d w}{d s}, M(s) \frac{d w}{d s}\right)\right| d s
\end{aligned}
$$

Received by the editors July 10, 1969 .

AMS 1969 subject classifications. Primary 3507, 3519; Secondary 3501, 3537.

Key words and phrases. Logarithmic convexity, differential inequalities, uniqueness and stability, problems of mixed type, non-well-posed problems, Chaplygin equation, linear elasticity, heat equation, Cauchy problem.

(1) This material is taken in part from the author's Ph.D. Thesis. The support of the National Science Foundation Graduate Fellowship Program and the Forschungsinstitut für Mathematik of the Eidgenössische Technische Hochschule is gratefully acknowledged.

Copyright (C) 1970, American Mathematical Society 
Here (, ) is the inner product on some Hilbert space $H$ (real or complex) and \|\| is the corresponding norm. The $k_{i}$ are given nonnegative constants. The linear operators $M(t)$ and $N(t)$ are assumed to be defined (for $t \in[0, T)$ ) on some dense domain $D \subseteq H$. The functions $w, d w / d t$ and $d^{2} w / d t^{2}$ are $D$ valued functions defined on $[0, T)$ with $T<\infty$. The vectors $w(0)$ and $(d w / d t)(0)$ constitute the Cauchy data for (1) or (2) subject to (3). In the present paper we consider inequalities of the form

$$
\|M(t) d w / d t-N(t) w\| \leqq \alpha(t, w) \quad(t \in[0, T))
$$

where

$$
\alpha^{2}(t, w)=k_{1}|(w, M(t) w)|+k_{2} \int_{0}^{t}|(w, M(s) w)| d s .
$$

The vector $w(0)$ then constitutes the Cauchy datum for the initial value problem for (4) subject to (5). We shall discuss the questions of uniqueness and stability of the null solution to the Cauchy problem for (4) and (5), cite some examples of these results and of those of [10] from the literature and compare our results with those of Agmon [1] and Agmon and Nirenberg [2].

The significant feature of the uniqueness and stability theorems concerning (1), (2) and (4) is that they are obtained independently of the type of the inequality. That is to say, the convexity method ignores the type of the inequality (if any). As long as certain other rather mild conditions on the operators are met it can be successfully applied to these inequalities.

Throughout this paper we shall use the symbols $w_{t}$ and $d w / d t$ (resp. $w_{t t}$ and $d^{2} w / d t^{2}$ ) interchangeably for the strong derivative of a vector valued function. Recall that if $B$ is a symmetric linear operator defined on $D_{B} \subseteq H$ such that $(x, B x) \geqq 0$ for all $x \in D_{B}$ then for all $x, y \in D_{B}$ we have $|\operatorname{Re}(x, B y)|^{2} \leqq|(x, B y)|^{2}$ $\leqq(x, B x)(y, B y)$. If $B(\cdot)$ is a family of symmetric linear operators defined on $[0, T)$ then we can define a new family of linear operators $B^{\prime}(\cdot)$ on $[0, T)$ whenever $B^{\prime}(t) x \equiv \lim _{h \rightarrow 0} h^{-1}[B(t+h) x-B(t) x]$ exists in the strong sense for each $t \in[0, T)$ and $x \in D_{B}$. If, moreover, $B(\cdot) u(\cdot)$ and $B(\cdot) v(\cdot)$ are strongly continuous for $u$ and $v$ in $C^{1}\left([0, T) ; D_{B}\right)$ then we have

$$
(d / d t)(u(t), B(t) v(t))=\left(u_{t}, B(t) v\right)+\left(u, B(t) v_{t}\right)+\left(u, B^{\prime}(t) v\right) .
$$

Equation (6) follows from the polarization identity for $(x, B y)$ and the special case for which $u \equiv v$ which was proved in [1], after a somewhat tedious but routine calculation. It can also be proved directly by forming the difference quotient as in [1].

If, as $t$ varies, $D_{B}(t)$, as well as $B(t)$, varies, then we cannot define

$$
B^{\prime}(t) x=\lim _{h \rightarrow 0} h^{-1}[B(t+h) x-B(t) x]
$$

because $x$ may fail to be in $D_{B}(t+h) \cap D_{B}(t)$ for all sufficiently small $h$. To get 
around this difficulty we follow the approach used in [1] and [2]. We define for $u, v, u_{t}$ and $v_{t}$ (assumed $D_{B}(t)$ valued)

$$
Q_{B}(u, v)(t) \equiv(d / d t)(u, B(t) v)-\left(u_{t}, B(t) v\right)-\left(u, B(t) v_{t}\right)
$$

(If $D_{B}(t)$ is independent of $t, Q_{B}(u, v)=\left(u, B^{\prime}(t) v\right)$.) We agree at the outset, in the case of nonconstant $D_{B}$, to replace estimates on the bilinear form $\left(x, B^{\prime} y\right)$ by analogous estimates on $Q_{B}(u, v)$. Thus, in Theorem 1, hypothesis A-2 would read $Q_{M}(u, u) \leqq k|(u, M(t) u)|$ for all $u:[0, T) \rightarrow H$ such that $u(t) \in D_{B}(t)$ and for some $k \geqq 0$, instead of $\left(x, M^{\prime}(t) x\right) \leqq k|(x, M(t) x)|$ for all $x \in D_{B}$ and $t \in[0, T)$. All of our results remain true in this more general setting. In the proofs, we simply write $Q_{B}(u, v)$ instead of $\left(u, B^{\prime} v\right)$ and use the analogous estimates.

This seemingly technical point becomes important when we consider initial boundary value problems for which conormal derivatives are given on parts of the "walls" of the space-time cylinder. Without explicitly mentioning the fact, we shall formulate our examples in $§ I V$ in this somewhat more general form.

II. Uniqueness. Instead of stating our results for the inequality (4) and the null solution, we shall state them for the equation

$$
M(t) d u / d t=N(t) u+f(t, u),
$$

where $f:[0, T) \times D \rightarrow H$ is continuous in both arguments jointly and satisfies, for $u(\cdot), v(\cdot) \in C^{1}([0, T) ; D)$

$$
\|f(t, u)-f(t, v)\| \leqq \alpha(t, u-v),
$$

where $\alpha$ is given by (5). The loss in generality is only an apparent one.

TheOREM 1 (UNIQUENESS). Let, for each $t \in[0, T), M(t)$ be a symmetric linear operator. Under each of the following five sets of conditions on $M(\cdot), N(\cdot)$ and $f(t, u)$, there is at most one solution to the initial value problem for (7) subject to (8):

A. For all $x \in D$ and $t \in[0, T)$,

1. $f \equiv 0$.

2. $\exists k \geqq 0 \ni\left(x, M^{\prime}(t) x\right) \leqq k|(x, M(t) x)|$.

3. $N(t)$ is symmetric and $(x, N(t) x)>0$ for $x \neq 0$.

4. $\exists k^{\prime} \geqq 0 \ni \forall x, y \in D,\left|\left(x, N^{\prime}(t) y\right)\right|^{2} \leqq k^{\prime}(x, N(t) x)(y, N(t) y)$.

B. For all $x \in D$ and $t \in[0, T)$,

1. $f \equiv 0$.

2. $(x, M(t) x)>0$ for $x \neq 0$.

3. $\exists k \geqq 0 \ni\left|\left(x, M^{\prime}(t) x\right)\right| \leqq k(x, M(t) x)$.

4. $N(t)$ is symmetric and

5. $\exists k^{\prime} \geqq 0 \ni\left(x, N^{\prime}(t) x\right) \geqq-k^{\prime}[|(x, N(t) x)|+(x, M(t) x)]$.

C. For all $x \in D$ and $t \in[0, T)$,

1. $f$ satisfies (8) with $\alpha$ given by (5) for some $k_{1}, k_{2} \geqq 0$.

2. $\exists \lambda>0 \ni(x, M(t) x) \geqq \lambda(x, x)$.

3. $\exists$ a constant $k \geqq 0 \ni\left|\left(x, M^{\prime}(t) x\right)\right| \leqq k(x, M(t) x)$. 
4. $N(t)$ is symmetric and

5. $\exists k^{\prime} \geqq 0 \ni\left(x, N^{\prime}(t) x\right) \geqq-k^{\prime}[|(x, N(t) x)|+(x, M(t) x)]$.

D. For all $x \in D$ and $t \in[0, T)$,

1. $f$ satisfies (8) as in $\mathrm{C}-1$.

2. $\exists \lambda>0 \ni(x, M(t) x) \geqq \lambda(x, x)$.

3. $\exists k \geqq 0 \ni\left|\left(x, M^{\prime}(t) x\right)\right| \leqq k(x, M(t) x)$.

4. $M^{-1}(t)$ is densely defined.

5. $N(t)=N_{1}(t)+N_{2}(t)+N_{3}(t)$ with $N_{1}(t)$ symmetric and $N_{i}(t)$ skew symmetric $\left(\operatorname{Re}\left(x, N_{i} x\right)=0\right)$ for $i=2,3$.

6. There is a constant $k^{\prime} \geqq 0$ such that

$$
\max \left\{\left\|N_{3} x\right\|^{2},-\operatorname{Re}\left(M^{-1} N_{2} x, N_{1} x\right),-\left(x, N_{1}^{\prime} x\right)\right\} \leqq k^{\prime}\left[\left|\left(x, N_{1} x\right)\right|+(x, M x)\right] .
$$

E. For all $x \in D$ and $t \in[0, T)$,

1. $f$ satisfies (8) as in $\mathrm{C}-1$.

2. $M \equiv I$ (identity).

3. $N(t)=N_{1}(t)+N_{2}(t)+N_{3}(t)$ as in D-5.

4. $\exists$ a constant $k \geqq 0$ such that

$$
\max \left\{\left\|N_{3} x\right\|^{2},-\operatorname{Re}\left(N_{2} x, N_{1} x\right),-\left(x, N_{1}^{\prime} x\right)\right\} \leqq k\|x\|\left(\left\|N_{1} x\right\|+\|x\|\right) .
$$

Before proving this theorem, some comments should be made. The technique used is that of logarithmic convexity. (See e.g. [1], [2], [6], [10], [11], [12].) If $w(t)$ is the difference of two solutions to (7) with $w(0)=0$, we try to construct a nonnegative real-valued functional $F(t, w(t))$ of $w(t)$ such that

(i) $F(t, w(t))=0 \Rightarrow w(t)=0 \forall t \in[0, T)$.

(ii) On every compact subset $K \subseteq[0, T)$, there exist constants $k_{1}(K), k_{2}(K)$ such that $F F^{\prime \prime}-\left(F^{\prime}\right)^{2} \geqq-k_{1} F F^{\prime}-k_{2} F^{2}\left({ }^{\prime}=d / d t\right)$.

(iii) $\exists \bar{t} \in[0, T) \ni F(\bar{t}, w(\bar{t}))=0$.

As is shown in [1], [2], [7] and [10] among other places, (ii) and (iii) imply $F \equiv 0$ and the uniqueness of the solutions then follows from (i).

In part $\mathrm{A}$ we must actually restrict our attention to uniqueness in the class of $C^{2}$ functions as can be seen in the proof below. Note that as we proceed from $\mathrm{A}$ to $\mathrm{E}$ we require successively more and more of $M(\cdot)$ while we demand correspondingly less and less of $N(\cdot)$ and $f$.

Part E of this theorem is not much different from Theorem 1 (ii) of [2] and has in fact much the same hypotheses. We include it here because the technique used in its proof is somewhat different from that used in [2].

We shall prove parts $A$ and $D$ in some detail, leave part $B$ to the reader and only sketch the proof of part $\mathrm{E}$. Part $\mathrm{C}$ will follow as a corollary of Theorem 2 in the next section. Throughout the proofs $k, k^{\prime}, k^{\prime \prime}, k_{1}, k_{2}, k_{3}$ will denote nonnegative generic constants which may depend upon $T$ but which are computable.

In order to establish part A, let $u$ and $v$ be solutions to $M u_{t}=N u$ with $u(0)=v(0)$ 
and let $w(t)=u(t)-v(t)$. Then, $M w_{t}=N w$ and $w(0)=0$. Define

$$
F(t)=\int_{0}^{t}(w, N w) d s .
$$

We see that $F(t)$ satisfies (i) and (iii) thanks to A-3. Since $w(0)=0$, we have that

$$
F^{\prime}(t)=(w, N w)=2 \int_{0}^{t} \operatorname{Re}\left(w_{s}, N w\right) d s+\int_{0}^{t}\left(w, N^{\prime} w\right) d s,
$$

and that

$$
F^{\prime \prime}(t)=2 \int_{0}^{t}\left[\left(w_{s}, N w_{s}\right)+\operatorname{Re}\left(w, N w_{s s}\right)+\operatorname{Re}\left(w, N^{\prime} w_{s}\right)\right] d s+\left(w, N^{\prime} w\right) .
$$

Therefore

$$
\begin{aligned}
F F^{\prime \prime}-\left(F^{\prime}\right)^{2}= & 4 S^{2}+2 F \int_{0}^{t}\left[\operatorname{Re}\left(w, N w_{s s}\right)-\left(w_{s}, N w_{s}\right)\right] d s \\
& +F\left\{2 \int_{0}^{t} \operatorname{Re}\left(w, N^{\prime} w_{s}\right) d s+\left(w, N^{\prime} w\right)\right\} \\
& -\left\{\left(\int_{0}^{t}\left(w, N^{\prime} w\right) d s\right)^{2}+4 \int_{0}^{t}\left(w, N^{\prime} w\right) d s \int_{0}^{t} \operatorname{Re}\left(w, N w_{s}\right) d s\right\}
\end{aligned}
$$

where

$$
S^{2} \equiv \int_{0}^{t}(w, N w) d s \int_{0}^{t}\left(w_{s}, N w_{s}\right) d s-\left(\int_{0}^{t} \operatorname{Re}\left(w, N w_{s}\right) d s\right)^{2} \geqq 0
$$

by Schwarz's inequality. We note also that

$$
\begin{aligned}
\left|\int_{0}^{t} \operatorname{Re}\left(w, N^{\prime} w_{s}\right) d s\right| & \leqq \int_{0}^{t}\left|\left(w, N^{\prime} w_{s}\right)\right| d s \\
& \leqq k\left[\int_{0}^{t}(w, N w) d s \int_{0}^{t}\left(w_{s}, N w_{s}\right) d s\right]^{1 / 2} \\
& \leqq k^{\prime \prime}\left[S^{2}+\frac{1}{4}\left(F^{\prime}-\int_{0}^{t}\left(w, N^{\prime} w\right) d s\right)^{2}\right]^{1 / 2} \\
& \leqq k_{1} S+k_{2} F+k_{3} F^{\prime}
\end{aligned}
$$

as we see from Schwarz's inequality, A-4, $|\operatorname{Re} z| \leqq|z|$ for $z$ complex and $\left(a^{2}+b^{2}\right)^{1 / 2} \leqq|a|+|b|$. Thus, after a short calculation we are led to the estimate

(13) $F F^{\prime \prime}-\left(F^{\prime}\right)^{2} \geqq 4 S^{2}-k_{1} F^{2}-k_{2} F S-k_{3} F F^{\prime}+2 F \int_{0}^{t}\left[\operatorname{Re}\left(w, N w_{s s}\right)-\left(w_{s}, N w_{s}\right)\right] d s$.

Now $(d / d s)\left(w_{s}, M w_{s}\right)=(d / d s)\left(w_{s}, N w\right)$ or

$$
\begin{aligned}
2 \operatorname{Re}\left(w_{s s}, M w_{s}\right)+\left(w_{s}, M^{\prime} w_{s}\right) & =\left(w_{s}, N w_{s}\right)+\left(w_{s s}, N w\right)+\left(w_{s}, N^{\prime} w\right) \\
& =\left(w_{s}, N w_{s}\right)+\left(w_{s s}, M w_{s}\right)+\left(w_{s}, N^{\prime} w\right) .
\end{aligned}
$$

Thus, taking real parts,

$$
\operatorname{Re}\left(w_{s s}, M w_{s}\right)-\left(w_{s}, N w_{s}\right)=\operatorname{Re}\left(w_{s}, N^{\prime} w\right)-\left(w_{s}, M^{\prime} w_{s}\right)
$$


The integral on the right of (13) can be rewritten as

$$
\int_{0}^{t}\left[\operatorname{Re}\left(w_{s s}, M w_{s}\right)-\left(w_{s}, N w_{s}\right)\right] d s
$$

or, from the above equation, as

$$
\int_{0}^{t} \operatorname{Re}\left(w_{s}, N^{\prime} w\right) d s-\int_{0}^{t}\left(w_{s}, M^{\prime} w_{s}\right) d s .
$$

From the estimate following the definition of $S^{2}$, we can bound the first of these integrals in terms of $k_{1} S+k_{2} F+k_{3} F^{\prime}$ for some computable $k_{i}$. Using condition A-2, we obtain, for the second of these,

$$
\begin{aligned}
-\int_{0}^{t}\left(w_{s}, M^{\prime} w_{s}\right) d s & \geqq-k \int_{0}^{t}\left|\left(w_{s}, M w_{s}\right)\right| d s \\
& \geqq-k \int_{0}^{t}\left|\left(w_{s}, N w\right)\right| d s \\
& \geqq-k\left\{\int_{0}^{t}(w, N w) d s \int_{0}^{t}\left(w_{s}, N w_{s}\right) d s\right\}^{1 / 2} \\
& \geqq-k_{1} S-k_{2} F-k_{3} F^{\prime} .
\end{aligned}
$$

Thus we have $F F^{\prime \prime}-\left(F^{\prime}\right)^{2} \geqq 4 S^{2}-k_{1} F S-k_{2} F^{2}-k_{3} F F^{\prime}$ for computable $k_{i}$. By a completion of squares we see that there are constants $a_{1}, a_{2}$ such that

$$
F F^{\prime \prime}-\left(F^{\prime}\right)^{2} \geqq-a_{1} F F^{\prime}-a_{2} F^{2} \text {. }
$$

Therefore $F(t)$ satisfies (ii) as well and thus $F \equiv 0$. Hence $w \equiv 0$ and the proof of part $\mathrm{A}$ is complete.

The result fails if A-2 is not fulfilled as is shown by the example $t u_{t}=-u_{x x}$ in $[0, \pi] \times[0, T)$. The solution $u(x, t)=t \sin x$ is a nontrivial solution vanishing on the bottom and sides of the cylinder.

In order to establish part $\mathrm{D}$ we must work harder. Let $w$ have the same significance as in the preceding proof. Define $f^{*}=f(t, u)-f(t, v)$. We have

$$
M w_{t}=N w+f^{*}=\sum_{i=1}^{3} N_{i} w+f^{*}, \quad w(0)=0,
$$

while $f^{*}$ satisfies

$$
\left\|f^{*}\right\| \leqq \alpha(t, w)
$$

Define

$$
F(t)=\int_{0}^{t}(w, M w) d s
$$

Let

$$
\begin{aligned}
& w^{*} \equiv w_{t}-M^{-1} N_{2} w \\
& w_{*} \equiv w^{*}-\frac{1}{2} M^{-1} N_{3} w=w_{t}-M^{-1} N_{2} w-\frac{1}{2} M^{-1} N_{3} w
\end{aligned}
$$


Since $w(0)=0$,

$$
\begin{aligned}
F^{\prime}(t) & =(w, M w)=2 \int_{0}^{t} \operatorname{Re}\left(w, M w_{s}\right) d s+\int_{0}^{t}\left(w, M^{\prime} w\right) d s \\
& =2 \int_{0}^{t} \operatorname{Re}\left(w, M w_{*}\right) d s+\int_{0}^{t}\left(w, M^{\prime} w\right) d s
\end{aligned}
$$

Here we have used D-5 and the extension of $M^{-1}(t)$ to all of $H$. We can also write, from (15),

$$
F^{\prime}(t)=2 \int_{0}^{t}\left(w, N_{1} w\right) d s+\int_{0}^{t}\left[2 \operatorname{Re}\left(f^{*}, w\right)+\left(w, M^{\prime} w\right)\right] d s .
$$

Therefore $F^{\prime \prime}$ exists and

$$
F^{\prime \prime}(t)=4 \int_{0}^{t} \operatorname{Re}\left(w_{s}, N_{1} w\right) d s+2 \int_{0}^{t}\left(w, N_{1}^{\prime} w\right) d s+2 \operatorname{Re}\left(w, f^{*}\right)+\left(w, M^{\prime} w\right) .
$$

Also, it is clear that

$$
\begin{aligned}
4 \int_{0}^{t} \operatorname{Re}\left(w_{s}, N_{1} w\right) d s= & 4 \int_{0}^{t} \operatorname{Re}\left(w^{*}, M w_{s}-N_{2} w-N_{3} w-f^{*}\right) d s \\
& +4 \int_{0}^{t} \operatorname{Re}\left(M^{-1} N_{2} w, N_{1} w\right) d s \\
= & 4 \int_{0}^{t} \operatorname{Re}\left(w^{*}, M w^{*}-N_{3} w\right) d s-4 \int_{0}^{t} \operatorname{Re}\left(w^{*}, f^{*}\right) d s \\
& +4 \int_{0}^{t} \operatorname{Re}\left(M^{-1} N_{2} w, N_{1} w\right) d s .
\end{aligned}
$$

We have, from the symmetry of $M$ and $M^{-1}$,

$$
\begin{aligned}
\left(w_{*}, M w_{*}\right) & =\left(w^{*}-\frac{1}{2} M^{-1} N_{3} w, M w^{*}-\frac{1}{2} N_{3} w\right) \\
& =\operatorname{Re}\left(w^{*}, M w^{*}-N_{3} w\right)+\frac{1}{4}\left(M^{-1} N_{3} w, N_{3} w\right)
\end{aligned}
$$

Thus

$$
\begin{aligned}
F^{\prime \prime}(t)= & 4 \int_{0}^{t}\left(w_{*}, M w_{*}\right) d s-\int_{0}^{t}\left(M^{-1} N_{3} w, N_{3} w\right) d s+2 \int_{0}^{t}\left(w, N_{1}^{\prime} w\right) d s \\
& +4 \int_{0}^{t} \operatorname{Re}\left[\left(M^{-1} N_{2} w, N_{1} w\right)-\left(w^{*}, f^{*}\right)\right] d s \\
& +2 \operatorname{Re}\left(f^{*}, w\right)+\left(w, M^{\prime} w\right)
\end{aligned}
$$

Now define

$$
S^{2}=\int_{0}^{t}(w, M w) d s \int_{0}^{t}\left(w_{*}, M w_{*}\right) d s-\left(\int_{0}^{t} \operatorname{Re}\left(w, M w_{*}\right) d s\right)^{2} .
$$


We see that

$$
\begin{aligned}
F F^{\prime \prime}-\left(F^{\prime}\right)^{2}= & 4 S^{2}+2 F \int_{0}^{t}\left[\left(w, N_{1}^{\prime} w\right)+2 \operatorname{Re}\left(N_{1} w, M^{-1} N_{2} w\right)-\frac{1}{2}\left(M^{-1} N_{3} w, N_{3} w\right)\right] d s \\
& -4 F \int_{0}^{t} \operatorname{Re}\left(w^{*}, f^{*}\right) d s+2 F\left[\operatorname{Re}\left(f^{*}, w\right)+\frac{1}{2}\left(w, M^{\prime} w\right)\right] \\
& -\left\{4 \int_{0}^{t} \operatorname{Re}\left(w, M_{*}\right) d s \int_{0}^{t}\left(w, M^{\prime} w\right) d s+\left(\int_{0}^{t}\left(w, M^{\prime} w\right) d s\right)^{2}\right\} .
\end{aligned}
$$

We must now show that each term on the right of (21) following $4 S^{2}$ can be estimated from below by a function of the form $-k_{1} F S-k_{2} F^{2}-k_{3} F F^{\prime}$ for some computable $k_{i}$. We first obtain an estimate for $\int_{0}^{t}\left|\left(w, N_{1} w\right)\right| d s$. We see from (15) and the skew symmetry of $N_{2}$ and $N_{3}$ that

$$
\begin{aligned}
\int_{0}^{t}\left|\left(w, N_{1} w\right)\right| d s & \leqq \int_{0}^{t}\left|\left(w, M w_{s}\right)\right| d s+\int_{0}^{t}\left|\left(w, f^{*}\right)\right| d s \\
& \leqq \int_{0}^{t}\left|\left(w, M w_{*}\right)\right| d s+\int_{0}^{t}\left|\left(w, f^{*}\right)\right| d s \\
& \leqq\left(\int_{0}^{t}(w, M w) d s \int_{0}^{t}\left(w_{*}, M w_{*}\right) d s\right)^{1 / 2}+\int_{0}^{t}\left|\left(w, f^{*}\right)\right| d s
\end{aligned}
$$

From (18), the definition of $S^{2}$, D-5 and the nonnegativity of $F^{\prime}$ we see that

$$
\begin{aligned}
\left(\int_{0}^{t}(w, M w) d s \int_{0}^{t}\left(w_{*}, M w_{*}\right) d s\right)^{1 / 2} & \leqq\left[S^{2}+\left(\int_{0}^{t} \operatorname{Re}\left(w, M w_{*}\right) d s\right)^{2}\right]^{1 / 2} \\
& \leqq S+\frac{1}{2}\left|F^{\prime}-\int_{0}^{t}\left(w, M^{\prime} w\right) d s\right| \\
& \leqq k_{1} S+k_{2} F+k_{3} F^{\prime}
\end{aligned}
$$

We also have, from (16) and D-2 that

$$
\begin{aligned}
\left|\left(w, f^{*}\right)\right| & \leqq k(w, M w)^{1 / 2}\left\|f^{*}\right\| \\
& \leqq k_{1}(w, M w)+k_{2}(w, M w)^{1 / 2}\left(\int_{0}^{t}(w, M w) d s\right)^{1 / 2} \\
& \leqq k_{1} F^{\prime}+k_{2} F
\end{aligned}
$$

since $|a b| \leqq a^{2}+b^{2}$. Since $F$ is monotone increasing,

$$
\int_{0}^{t}\left|\left(w, f^{*}\right)\right| d s \leqq k F .
$$

(Here $k$ depends upon $T$.) Thus, combining (22), (23) and (25), we obtain

$$
\int_{0}^{t}\left|\left(w, N_{1} w\right)\right| d s \leqq k_{1} S+k_{2} F+k_{3} F^{\prime}
$$

From D-2, we see that the family $M^{-1}(\cdot)$ is uniformly bounded and since

$$
\left|\left(M^{-1} N_{3} x, N_{3} x\right)\right| \leqq\left\|M^{-1} N_{3} x\right\|\left\|N_{3} x\right\| \leqq k\left\|N_{3} x\right\|^{2}
$$


we see from D-6 and (26) that there are constants $k_{i}$ such that

$$
\max \left\{\begin{array}{l}
-\int_{0}^{t}\left(w, N_{1}^{\prime} w\right) d s \\
-\int_{0}^{t} \operatorname{Re}\left(N_{1} w, M^{-1} N_{2} w\right) d s \\
\int_{0}^{t}\left(M^{-1} N_{3} w, N_{3} w\right) d s
\end{array}\right\} \leqq k_{1} S+k_{2} F+k_{3} F^{\prime}
$$

Now from D-3 and (24) we have that

$$
\max \left(\left|\operatorname{Re}\left(f^{*}, w\right)\right|,\left|\left(w, M^{\prime} w\right)\right|\right) \leqq k_{1} S+k_{2} F+k_{3} F^{\prime} .
$$

Moreover,

$$
\begin{aligned}
\left|\int_{0}^{t} \operatorname{Re}\left(w^{*}, f^{*}\right) d s\right| \leqq & \int_{0}^{t}\left\|w^{*}\right\|\left\|f^{*}\right\| d s \\
\leqq & \int_{0}^{t}\left\|w_{*}+\frac{1}{2} M^{-1} N_{3} w\right\|\left\|f^{*}\right\| d s \\
\leqq & k_{1} \int_{0}^{t}\left(w_{*}, M_{*} w^{1 / 2}\left\|f^{*}\right\| d s+k_{2} \int_{0}^{t}\left\|M^{-1} N_{3} w\right\|\left\|f^{*}\right\| d s\right. \\
\leqq & k_{1}\left(\int_{0}^{t}\left(w_{*}, M w_{*}\right) d s \int_{0}^{t}\left\|f^{*}\right\|^{2} d s\right)^{1 / 2} \\
& +k_{2}\left(\int_{0}^{t}\left\|N_{3} w\right\|^{2} d s \int_{0}^{t}\left\|f^{*}\right\|^{2} d s\right)^{1 / 2}
\end{aligned}
$$

Now from the monotonicity of $F, \int_{0}^{t}\left\|f^{*}\right\|^{2} d s \leqq k_{1} F$. Thus, since $|a b| \leqq a^{2}+b^{2}$ we obtain

$$
\begin{aligned}
\left|\int_{0}^{t} \operatorname{Re}\left(w^{*}, f^{*}\right) d s\right| \leqq & k_{1}\left(\int_{0}^{t}\left(w_{*}, M w_{*}\right) d s \int_{0}^{t}(w, M w) d s\right)^{1 / 2} \\
& +k_{2} \int_{0}^{t}\left\|N_{3} w\right\|^{2} d s+k_{3} F \\
\leqq & k_{1} S+k_{2} F+k_{3} F^{\prime} .
\end{aligned}
$$

Here we made use of D-6 and (26). Also it is easy to see that

$$
\begin{aligned}
\mid 4 \int_{0}^{t} \operatorname{Re}\left(w, M w_{*}\right) d s \int_{0}^{t}\left(w, M^{\prime} w\right) d s+ & \left(\int_{0}^{t}\left(w, M^{\prime} w\right) d s\right)^{2} \mid \\
& \leqq k_{1} F^{2}+k_{2} F S+k_{3} F F^{\prime} .
\end{aligned}
$$

Thus $F F^{\prime \prime}-\left(F^{\prime}\right)^{2} \geqq 4 S^{2}-k_{1} F S-k_{2} F F^{\prime}-k_{3} F^{2}$ and a completion of squares yields $F F^{\prime \prime}-\left(F^{\prime}\right)^{2} \geqq-k_{1} F F^{\prime}-k_{2} F^{2}$. Since $F(0)=0, F \equiv 0$ in $[0, T)$ and $w \equiv 0$.

In order to prove part $\mathrm{E}$ we need only note that if $M=I$ then we have

$$
\begin{aligned}
F F^{\prime \prime}-\left(F^{\prime}\right)^{2}= & 4 S^{2}+2 F \int_{0}^{t}\left[\left(w, N_{1}^{\prime} w\right)+2 \operatorname{Re}\left(N_{1} w, N_{2} w\right)-\frac{1}{2}\left\|N_{3} w\right\|^{2}\right] d s \\
& -4 F \int_{0}^{t} \operatorname{Re}\left(w^{*}, f^{*}\right) d s+2 F \operatorname{Re}\left(f^{*}, w\right) .
\end{aligned}
$$


We need only show that we can bound the integral

$$
\int_{0}^{t}\|w\|\left\|N_{1} w\right\| d s
$$

above by a function of the form $k_{1} S+k_{2} F+k_{3} F^{\prime}$. Now we have for any real $a, b$ and $\alpha>0,|a b| \leqq \alpha a^{2} / 2+b^{2} / 2 \alpha$ and thus

$$
\begin{aligned}
\int_{0}^{t}\|w\|\left\|N_{1} w\right\| d s \leqq & \int_{0}^{t}\|w\|\left\|w_{s}-N_{2} w-N_{3} w-f^{*}\right\| d s \\
\leqq & \int_{0}^{t}\|w\|\left\|w_{*}\right\| d s+\int_{0}^{t}\|w\|\left\|\frac{1}{2} N_{3} w+f^{*}\right\| d s \\
\leqq & \left(\int_{0}^{t}\|w\|^{2} d s \int_{0}^{t}\left\|w_{*}\right\|^{2} d s\right)^{1 / 2} \\
& +\frac{1}{2} \int_{0}^{t}\|w\|\left\|N_{3} w\right\| d s+\int_{0}^{t}\|w\|\left\|f^{*}\right\| d s \\
\leqq & \left\{S^{2}+\frac{1}{4}\left(F^{\prime}\right)^{2}\right\}^{1 / 2}+\frac{\alpha}{4} \int_{0}^{t}\left\|N_{3} w\right\|^{2} d s+\left(\frac{1}{4 \alpha}+k_{1}\right) \int_{0}^{t}\|w\|^{2} d s \\
\leqq & S+\frac{1}{2} F^{\prime}+k_{1}(\alpha) F+\frac{\alpha k}{4} \int_{0}^{t}\|w\|\left\|N_{1} w\right\| d s .
\end{aligned}
$$

Here we have used Schwarz's inequality and the estimate (16) together with the monotonicity of $F$ on $\int_{0}^{t}\|w\|\left\|f^{*}\right\| d s$. We choose $\alpha$ so small that $1-\alpha k / 4>0$, transpose the last integral on the right and divide by $1-\alpha k / 4$ to obtain

$$
\int_{0}^{t}\|w\|\left\|N_{1} w\right\| d s \leqq k_{1} S+k_{2} F+k_{3} F^{\prime}
$$

Now we may proceed exactly as before.

We cannot replace the term $\left|\left(x, N_{1} x\right)\right|$ on the right of D-6 by $\|x\|\left\|N_{1} x\right\|$. The difficulty arises in trying to estimate

$$
\int_{0}^{t}\|w\|\left\|N_{1} w\right\| d s \leqq \int_{0}^{t}\|w\|\left\|M w_{*}\right\| d s+\int_{0}^{t}\|w\|\left\|\frac{1}{2} N_{3} w+f^{*}\right\| d s .
$$

We cannot always be sure that there exists a constant $k$ such that

or that

$$
\int_{0}^{t}\|w\|\left\|M w_{*}\right\| d s \leqq k\left(\int_{0}^{t}(w, M w) d s \int_{0}^{t}\left(w_{*}, M w_{*}\right) d s\right)^{1 / 2}
$$

$$
(y, y)(M x, M x) \leqq k(x, M x)(y, M y) .
$$

As an example of when this latter fails, let $H=l^{2}$ with orthonormal basis vectors $e_{1}, e_{2}, \ldots$ Define $M e_{i}=i e_{i}, i=1,2, \ldots$ The domain of $M$ is dense, the range of $M$ is dense, $(x, M x) \geqq(x, x)$ for all $x \in D_{M}$. Define $x^{n}=\sum_{j=1}^{n} j^{-3 / 2} e_{j}$. Then $\left(x^{n}, M x^{n}\right)=\sum_{j=1}^{n} j^{-2},\left(M x^{n}, M x^{n}\right)=\sum_{j=1}^{n} j^{-1}$ and $\left(x^{n}, x^{n}\right)=\sum_{j=1}^{n} j^{-3}$. We see that 
there does not exist $k$ such that for all $n$,

$$
\left(\sum_{j=1}^{n} j^{-1}\right)\left(\sum_{j=1}^{n} j^{-3}\right) \leqq k\left(\sum_{j=1}^{n} j^{-2}\right)^{2} .
$$

Thus we may not always be able to bound $\int_{0}^{t}\|w\|\left\|M w_{*}\right\| d s$ in terms of $k_{1} S+k_{2} F+k_{3} F^{\prime}$ for some computable $k_{i}$.

Theorem 1 holds for $T=\infty$ with the $k$ 's in the hypotheses replaced by locally bounded functions of $t$. We simply repeat the above arguments on compact subsets of $[0, \infty)$. Moreover, we remark that under the change of variable $t \rightarrow-t$ we may reduce the backward problem for (7) to the forward problem for

$$
M u_{t}=-N(-t) u-f(-t, u) .
$$

Then the various hypotheses for $-N,-N_{1},-N_{2}$ and $-N_{3}$ can be deduced directly from those for $N, N_{1}, N_{2}$ and $N_{3}$. (The exception being Theorem 1, part A, where we must write the equation as $-M(-t) w_{t}=N(-t) w$. Then the hypotheses for $-M(-t)$ can be deduced directly from those for $M(t)$.)

III. Stability. In this section we take up the question of the stability of solutions to (1). By stability, we mean here stability in the sense of F. John [5] whose definitions we repeat for the convenience of the reader in a somewhat abbreviated form. Let $\Phi$ and $R$ be sets. Let $S \subseteq R$. Let $N_{F}$ and $N_{U}$ be normed linear spaces of functions on $\Phi$ and $R$ respectively with norms \|\|$^{\Phi}$ and \|\|$^{R}$. Let $F$ and $U$ be given subsets of $N_{F}$ and $N_{U}$ respectively and let $\Omega: F \rightarrow U$ be given. $F$ is called the space of "admissible data" and $U$ a space of "admissible solutions." Neither may be linear spaces nor need $\Omega$ be linear. The question of uniqueness of solutions in the class $U$ corresponds to the question of whether or not $\Omega$ is well defined, i.e. to the question of whether or not $\Omega$ is a function. In general $\Omega$ may not be continuous (i.e. the solutions may not be stable in the sense of Hadamard). However, the following situation often obtains: Let $N_{S}$ denote the elements of $N_{U}$ restricted to $S$ and suppose that on $N_{S}$ we may define a new norm \|\|$^{S}$. For any $M>0$ we define

$$
\begin{aligned}
& U_{M}=\left\{u \in U \mid\|u\|^{R} \leqq M\right\}, \\
& F_{M}=\left\{f \in F \mid \Omega f \in U_{M}\right\}=\Omega^{-1}\left(U_{M}\right) .
\end{aligned}
$$

Then it may happen that there exist constants $A=A(S, M) \alpha=\alpha(S, M)$ with $\alpha \in(0,1]$ such that for $f, f^{\prime} \in F$

$$
\left\|\Omega f-\Omega f^{\prime}\right\|^{S} \leqq A\left(\left\|f-f^{\prime}\right\|^{\Phi}\right)^{\alpha}\left(\left\|\Omega f-\Omega f^{\prime}\right\|^{R}\right)^{1-\alpha} .
$$

Then, if $f, f^{\prime} \in F_{M}$, we have

$$
\left\|\Omega f-\Omega f^{\prime}\right\|^{S} \leqq A \cdot(2 M)^{1-\alpha}\left(\left\|f-f^{\prime}\right\|^{\Phi}\right)^{\alpha} \leqq A^{*}\left(\left\|f-f^{\prime}\right\|^{\Phi}\right)^{\alpha} .
$$

Under these conditions we call the mapping $\Omega$ Hölder continuously stable with respect to the triple $(F, U, S)$ and the constant $M$. A number of workers ([6], [7], 
[11], [12], [13], [14]) have given numerous examples of this type of stability and physical justification for it. In our applications $R=[0, T), \quad \Phi=\{0\}$ and $S=S\left(t_{0}\right)=\left[0, t_{0}\right)$ for $t_{0} \in(0, T)$.

THEOREM 2 (StABILITY). Let the operator families $M(\cdot)$ and $N(\cdot)$ satisfy the hypotheses of Theorem 1 , part $\mathrm{C}$. Suppose $u(\cdot)$ satisfies $(7)$ and $\varphi \in C^{1}([0, T) ; D)$ is such that

$$
L \varphi \equiv M \varphi_{t}-N \varphi-f(t, \varphi)
$$

is defined. Let $w=u-\varphi$ and suppose $T<\infty$. Then there exist constants $\alpha_{i} \geqq 0, i=1,2$, 3,4 , such that the function

$$
\begin{aligned}
F(t)= & \int_{0}^{t}\left(w, M w^{\prime}\right) d s+(T-t)(w, M w)_{0}+\alpha_{1}(w, M w)_{0}+\alpha_{2}\left|(w, N w)_{0}\right| \\
& +\alpha_{3} \sup _{[0, T)}\|L \varphi\|^{2}+\alpha_{4} \int_{0}^{T}\|L \varphi\|^{2} d s, \quad t \in[0, T)
\end{aligned}
$$

satisfies

$$
F F^{\prime \prime}-\left(F^{\prime}\right)^{2} \geqq-k_{1} F F^{\prime}-k_{2} F^{2} \quad\left({ }^{\prime}=d / d t\right),
$$

for some nonnegative computable $k_{1}$ and $k_{2}$.

The useful consequence of (36) is the fact that any nonnegative $F(t)$ which satisfies (36) (and is therefore either always zero or never zero [2], [10]) satisfies

$$
F(t) \leqq L[F(0)]^{1-v(t)}[F(T)]^{v(t)}
$$

where, with $k_{1}$ and $k_{2}$ as in (36),

$$
\nu(t)=\left(1-\exp \left(-k_{1} t\right)\right) /\left(1-\exp \left(-k_{1} T\right)\right)
$$

and

$$
L=\exp \left[\left|k_{2}\right| T^{2} \exp \left(\left|k_{1}\right| T\right)\right] .
$$

Let us regard the constants $\alpha_{i}$ as unknowns for the moment. Any such $F(t)$ may be written in the form

$$
F(t)=\int_{0}^{t}(w, M w) d s+(T-t)(w, M w)_{0}+P^{2}=\int_{0}^{t}(w, M w)+Q^{2}
$$

where $P^{2}$ and $Q^{2}$ are data terms. We shall simply treat $P^{2}$ as an unknown and see how we are led to define it in order that $F(t)$ satisfy (36). We have

$$
\begin{aligned}
F^{\prime}(t) & =(w, M w)-(w, M w)_{0}=\int_{0}^{t} \frac{d}{d s}(w, M w) d s \\
& =2 \int_{0}^{t} \operatorname{Re}\left(w, M w_{s}\right) d s+\int_{0}^{t}\left(w, M^{\prime} w\right) d s .
\end{aligned}
$$

From $M u_{t}=N u+f(t, u)$ and (34) we see that

$$
M w_{t}=N w+f^{*}-L \varphi
$$


where $f^{*}=f(t, u)-f(t, \varphi)$. Therefore

$$
F^{\prime}(t)=2 \int_{0}^{t}(w, N w) d s+\int_{0}^{t}\left(w, M^{\prime} w\right) d s+2 \int_{0}^{t} \operatorname{Re}\left[\left(w, f^{*}\right)-(w, L \varphi)\right] d s
$$

Thus $F^{\prime \prime}$ exists and, using C-4,

since

$$
\begin{aligned}
F^{\prime \prime}(t)= & 4 \int_{0}^{t} \operatorname{Re}\left(w_{s}, N w\right) d s+2\left\{\int_{0}^{t}\left(w, N^{\prime} w\right) d s+(w, N w)_{0}\right\} \\
& +\left(w, M^{\prime} w\right)+2 \operatorname{Re}\left[\left(w, f^{*}\right)-(w, L \varphi)\right]
\end{aligned}
$$

$$
(w, N w)=(w, N w)_{0}+\int_{0}^{t} \frac{d}{d s}(w, N w) d s .
$$

Solving (42) for $N w$, substituting this in the above equation and writing

where

$$
F^{\prime \prime}(t)=4 \int_{0}^{t}\left(w_{s}, M w_{s}\right) d s+Q^{*}(t)
$$

we obtain

$$
\begin{aligned}
Q^{*}(t) \equiv & 2 \int_{0}^{t}\left(w, N^{\prime} w\right) d s+\left(w, M^{\prime} w\right)+2\left[\operatorname{Re}\left(w, f^{*}\right)-\operatorname{Re}(w, L \varphi)\right] \\
& +4 \int_{0}^{t} \operatorname{Re}\left[\left(w_{s}, L \varphi\right)-\left(w_{s}, f^{*}\right)\right] d s+2(w, N w)_{0}
\end{aligned}
$$

$$
\begin{aligned}
F F^{\prime \prime}-\left(F^{\prime}\right)^{2}= & 4 S^{2}+4 Q^{2} \int_{0}^{t}\left(w_{s}, M w_{s}\right) d s+Q^{*} F \\
& -\left\{4 \int_{0}^{t} \operatorname{Re}\left(w, M w_{s}\right) d s \int_{0}^{t}\left(w, M^{\prime} w\right) d s+\left(\int_{0}^{t}\left(w, M^{\prime} w\right) d s\right)^{2}\right\} \\
\equiv & 4 S^{2}+4 Q^{2} \int_{0}^{t}\left(w_{s}, M w_{s}\right) d s+Q^{*} F-R^{*}
\end{aligned}
$$

where $S^{2}$ has the same definition as used in the proof of Theorem 1, part D. (Here $w_{*}=w_{t}$ as $N_{2}=N_{3}=0$.) We now try to find lower bounds for the terms $Q^{*} F$ and $-R^{*}$ of the form $-k_{1} S F-k_{2} F F^{\prime}-k_{3} F^{2}$. This will force us to choose $P^{2}$ of the above form. We need the following elementary inequalities for whose verification one needs only C-3 and Schwarz's inequality:

$$
\begin{gathered}
\int_{0}^{t}(w, M w) d s=F-Q^{2} \leqq F-P^{2} \leqq F \\
\left|F^{\prime}\right| \leqq(w, M w)+(w, M w)_{0} \leqq F^{\prime}+2(w, M w)_{0} ;
\end{gathered}
$$

$$
\begin{aligned}
\left(\int_{0}^{t}(w, M w) d s \int_{0}^{t}\left(w_{s}, M w_{s}\right) d s\right)^{1 / 2} & \leqq\left[S^{2}+\frac{1}{2}\left|F^{\prime}-\int_{0}^{t}\left(w, M^{\prime} w\right) d s\right|^{2}\right]^{1 / 2} \\
& \leqq k_{1} S+k_{2}\left|F^{\prime}\right|+k_{3} \int_{0}^{t}(w, M w) d s \\
& \leqq k_{1} S+k_{2} F+k_{3} F^{\prime}+k_{4}(w, M w)_{0}-k_{5} Q^{2}
\end{aligned}
$$


Here the $k_{i}$ 's are nonnegative computable constants. Using these we see, after a short calculation, that

$$
\left|R^{*}\right| \leqq k_{1} F S+k_{2} F^{2}+k_{3} F F^{\prime}+k_{4}(w, M w)_{0} F-k_{5} Q^{2} F .
$$

We now take up the more difficult problem of finding bounds for $Q^{*}$ of the desired form. From C-5, $N w=M w_{t}-f^{*}+L \varphi$ and Schwarz's inequality there are constants $k_{i} \geqq 0$ such that

$$
\begin{aligned}
-\int_{0}^{t}\left(w, N^{\prime} w\right) d s \leqq & k_{1}\left(\int_{0}^{t}(w, M w) d s \int_{0}^{t}\left(w_{s}, M w_{s}\right) d s\right)^{1 / 2}+k_{2} \int_{0}^{t}|(w, L \varphi)| d s \\
& +k_{3} \int_{0}^{t}(w, M w) d s+k_{4} \int_{0}^{t}\left|\left(w, f^{*}\right)\right| d s .
\end{aligned}
$$

Now since $\int_{0}^{t}(w, M w) d s$ is monotone increasing, C-2 and C-3 hold, $\left\|f^{*}\right\|$ satisfies $\left\|f^{*}\right\| \leqq \alpha(t, w)$ and $|a b| \leqq a^{2}+b^{2}$, we see that there are constants $k_{i} \geqq 0$ such that

$$
\begin{aligned}
\max \left\{\begin{array}{l}
\left|\left(w, M^{\prime} w\right)\right| \\
\left|\operatorname{Re}\left(w, f^{*}\right)\right| \\
\left|\int_{0}^{t}\left(w_{s}, f^{*}\right) d s\right| \\
\int_{0}^{t}\left|\left(w, f^{*}\right)\right| d s
\end{array}\right\} \leqq \max \left\{\begin{array}{l}
k_{1}(w, M w)+k_{2}\left((w, M w) \int_{0}^{t}(w, M w) d s\right)^{1 / 2} \\
k_{3}\left(\int_{0}^{t}(w, M w) d s \int_{0}^{t}\left(w_{s}, M w_{s}\right) d s\right)^{1 / 2} \\
k_{4} \int_{0}^{t}(w, M w) d s
\end{array}\right\} \\
\qquad k_{5}(w, M w)+k_{6} \int_{0}^{t}(w, M w) d s \\
+k_{7}\left(\int_{0}^{t}(w, M w) d s \times \int_{0}^{t}\left(w_{s}, M w_{s}\right) d s\right)^{1 / 2}
\end{aligned}
$$

It is clear that for some nonnegative $k_{i}$ 's

$$
\max \left\{\begin{aligned}
&|2 \operatorname{Re}(w, L \varphi)| t \\
& \int_{0}^{t}|(w, L \varphi)| d s
\end{aligned}\right\} \leqq \begin{aligned}
& k_{1}(w, M w)+k_{2} \int_{0}^{t}(w, M w) d s \\
& +k_{3} \sup _{[0, T)}\|L \varphi\|^{2}+k_{4} \int_{0}^{T}\|L \varphi\|^{2} d s .
\end{aligned}
$$

Also $(w, M w) \leqq F^{\prime}+(w, M w)_{0}$. Combining these last four estimates in the definition of $Q^{*}$ and using (45), (46) and (47) we find that there exist computable constants $k_{i} \geqq 0$ such that

$$
\begin{aligned}
-Q^{*} \leqq & k_{1} S+k_{2} F+k_{3} F^{\prime}+k_{4}(w, M w)_{0}+k_{5}\left|(w, N w)_{0}\right| \\
& +k_{6} \sup _{[0, T)}\|L \varphi\|^{2}+k_{7} \int_{0}^{T}\|L \varphi\|^{2} d s-k_{8} Q^{2}+4 \int_{0}^{t} \operatorname{Re}\left(w_{s}, L \varphi\right) d s
\end{aligned}
$$

Now for the tricky part. If we combine (47) and (48) with (43) we obtain for 
some computable, nonnegative $k_{i}$

$$
\begin{aligned}
F F^{\prime \prime}-\left(F^{\prime}\right)^{2} \geqq & 4 S^{2}+4 Q^{2} \int_{0}^{t}\left(w_{s}, M w_{s}\right) d s-4 F \int_{0}^{t} \operatorname{Re}\left(w_{s}, L \varphi\right) d s \\
& +k_{1}\left[Q^{2}-k_{2}(w, M w)_{0}-k_{3}\left|(w, N w)_{0}\right|\right. \\
& \left.-k_{4} \sup _{[0, T)}\|L \varphi\|^{2}-k_{5} \int_{0}^{T}\|L \varphi\|^{2} d s\right] F \\
& -k_{6} F S-k_{7} F F^{\prime}-k_{8} F^{2} .
\end{aligned}
$$

It is the estimate of the third term on the right of (49) which must be handled delicately. First we choose the quantity $P^{2}$ so that $Q^{2}=P^{2}+(T-t)(w, M w)_{0}$ exceeds

$$
k_{2}(w, M w)_{0}+k_{3}\left|(w, N w)_{0}\right|+k_{4} \sup _{[0, T)}\|L \varphi\|^{2}+k_{5} \int_{0}^{T}\|L \varphi\|^{2} d s .
$$

That is, we choose the $\alpha_{i}$ in (35) so that $\alpha_{i}>k_{i+1}$ for $i=1,2,3,4$. Then we see that there exist nonnegative constants $k, k^{\prime}$ such that $\int_{0}^{T}\|L \varphi\|^{2} d s \leqq k F,(w, M w)_{0} \leqq k^{\prime} F$. The second of these allows us to conclude that there are computable $k_{i}$ such that

$$
\left(\int_{0}^{t}(w, M w) d s \int_{0}^{t}\left(w_{s}, M w_{s}\right) d s\right)^{1 / 2} \leqq k_{1} F+k_{2} S+k_{3} F^{\prime}
$$

We see that for some computable $k_{1}$

$$
\begin{aligned}
F \int_{0}^{t} \operatorname{Re}\left(w_{s}, L \varphi\right) d s & -Q^{2} \int_{0}^{t}\left(w_{s}, M w_{s}\right) d s \\
\leqq & k_{1}\left(F-Q^{2}\right)\left(\int_{0}^{t}\left(w_{s}, M w_{s}\right) d s \int_{0}^{T}\|L \varphi\|^{2} d s\right)^{1 / 2} \\
& +Q^{2}\left[k_{1}\left(\int_{0}^{t}\left(w_{s}, M w_{s}\right) d s \int_{0}^{T}\|L \varphi\|^{2} d s\right)^{1 / 2}-\int_{0}^{t}\left(w_{s}, M w_{s}\right) d s\right]
\end{aligned}
$$

Applying the arithmetric geometric mean inequality $|a b| \leqq \alpha a^{2} / 2+b^{2} / 2 \alpha$ for $\alpha>0$ with $\alpha$ such that $\alpha k_{1} / 2=1$ to the first term in braces on the right of the above, we obtain

$$
\begin{aligned}
& F \int_{0}^{t} \operatorname{Re}\left(w_{s}, L \varphi\right) d s-Q^{2} \int_{0}^{t}\left(w_{s}, M w_{s}\right) d s \\
& \leqq k_{1}\left[\left(\int_{0}^{t}(w, M w) d s \int_{0}^{t}\left(w_{s}, M w_{s}\right) d s\right)^{1 / 2}\left(\int_{0}^{t}(w, M w) d s \int_{0}^{T}\|L \varphi\|^{2} d s\right)^{1 / 2}\right] \\
&+k_{2} Q^{2} \int_{0}^{T}\|L \varphi\|^{2} d s .
\end{aligned}
$$

From (50), $\int_{0}^{T}\|L \varphi\|^{2} d s \leqq k F$ and $Q^{2} \leqq F$ we obtain

$$
F \int_{0}^{t} \operatorname{Re}\left(w_{s}, L \varphi\right) d s-Q^{2} \int_{0}^{t}\left(w_{s}, M w_{s}\right) d s \leqq k_{1} F S+k_{2} F^{2}+k_{3} F F^{\prime}
$$


for some computable $k_{i}$. Then, making use of (51) and the choice of the constants $\alpha_{i}$ in

$$
P^{2} \equiv \alpha_{1}(w, M w)_{0}+\alpha_{2}\left|(w, N w)_{0}\right|+\alpha_{3} \sup _{[0, T)}\|L \varphi\|^{2}+\alpha_{4} \int_{0}^{T}\|L \varphi\|^{2} d s,
$$

we see from (49) that for some computable $k_{i}$

$$
F F^{\prime \prime}-\left(F^{\prime}\right)^{2} \geqq 4 S^{2}-k_{1} F S-k_{2} F F^{\prime}-k_{3} F^{2}
$$

and thus that $F$ satisfies (36) with the $\alpha_{i}$ as above.

We remark that if we had defined $P^{2}$ by

$$
P^{2} \equiv \beta_{1}(w, M w)_{0}+\beta_{2}\|N w\|_{0}^{2}+\beta_{3} \sup _{[0, T)}\|L \varphi\|^{2}+\beta_{4} \int_{0}^{T}\|L \varphi\|^{2} d s
$$

where $\beta_{i} \geqq \alpha_{i}, i=1,2,3,4$, instead of as defined above, then

$$
G_{1}(t) \equiv \int_{0}^{t}(w, M w) d s+(T-t)(w, M w)_{0}+P^{2}
$$

would also satisfy an inequality of the form $(36)\left({ }^{2}\right)$. Moreover, we see from the identity

$$
\operatorname{Re}(w, L \varphi)=\operatorname{Re}(w, L \varphi)_{0}+\int_{0}^{t} \operatorname{Re}\left(w_{s}, L \varphi\right) d s+\int_{0}^{t} \operatorname{Re}\left(w,(L \varphi)_{s}\right) d s
$$

that we may replace the coefficient of $\beta_{3}$ by

$$
\gamma_{1}\|L \varphi\|_{0}^{2}+\gamma_{2} \int_{0}^{T}\left\|(L \varphi)_{s}\right\|^{2} d s
$$

for some computable $\gamma_{1}$ and $\gamma_{2}$. This will also necessitate some adjustment in the coefficients $\beta_{1}, \beta_{2}$ and $\beta_{4}$. We need only modify the preceding argument to the extent that we must estimate

$$
\alpha F \int_{0}^{t}\left(w_{s}, L \varphi\right) d s-Q^{2} \int_{0}^{t}\left(w_{s}, M w_{s}\right) d s
$$

for $\alpha=1 / 2$ instead of for $\alpha=1$ and observe that the bound for

$$
\max \left\{|2 \operatorname{Re}(w, L \varphi)|, \int_{0}^{t}|(w, L \varphi)| d s\right\}
$$

must include terms of the form $\|L \varphi\|_{0}^{2}, \int_{0}^{T}\left\|(L \varphi)_{s}\right\|^{2} d s$ and $(w, M w)_{0}$ in addition to those previously given.

COROLlaRy 1. The initial value problem for (7) under the hypotheses of Theorem 1 , part $\mathrm{C}$ has at most one solution. (That is, Theorem 1, part $\mathrm{C}$ is true.)

$\left.{ }^{2}\right)$ If $F F^{\prime \prime}-\left(F^{\prime}\right)^{2} \geqq-k_{1} F F^{\prime}-k_{2} F^{2}, k_{1}, k_{2} \geqq 0$ and $F^{\prime} \geqq 0$, and if $G(t)=F(t)+K$ where $K \geqq 0$ is constant then $G G^{\prime \prime}-\left(G^{\prime}\right)^{2} \geqq-k_{1} G G^{\prime}-k_{2} G^{2}$. 
Proof. Let $u$ and $\varphi$ be solutions to (7) such that $u(0)=\varphi(0)$ and let $w=u-\varphi$. Thus $L \varphi=0$ and $w(0)=0$. Thus $F(t)$ (or $\left.G_{1}(t)\right)$ can be reduced to $F(t)=\int_{0}^{t}(w, M w) d s$ and still satisfies an inequality of the form (36) and, in addition, $F(0)=0$. Thus $F \equiv 0$ and hence $u \equiv \varphi$.

Corollary 2. Let $\varphi_{1}$ and $\varphi_{2} \in C^{1}([0, T) ; D)$. Then under the hypotheses of Theorem 1-C, there exist nonnegative constants $\alpha_{1}, \alpha_{2}, \alpha_{3}, \alpha_{4}, k_{1}$ and $k_{2}$ such that

$$
\int_{0}^{t}(w, M w) d s \leqq k_{2} Q^{2(1-v(t))} \cdot\left(\int_{0}^{T}(w, M w) d s+Q^{2}\right)^{v(t)}
$$

where $T<\infty, w=\varphi_{1}-\varphi_{2}, v(t)=\left(1-\exp \left(-k_{1} t\right)\right) /\left(1-\exp \left(-k_{1} T\right)\right)$ and

(54) $Q^{2}=\alpha_{1}(w, M w)_{0}+\alpha_{2}\left|(w, N w)_{0}\right|+\alpha_{3} \sup _{[0, T)}\left\|L \varphi_{1}-L \varphi_{2}\right\|^{2}+\alpha_{4} \int_{0}^{T}\left\|L \varphi_{1}-L \varphi_{2}\right\|^{2} d s$.

This result remains true (with possibly different $\alpha$ 's) if we replace $\left|(w, N w)_{0}\right|$ by $\|N w\|_{0}^{2}$. Also analogous results hold under the hypotheses of $\mathrm{A}, \mathrm{B}, \mathrm{D}$ and $\mathrm{E}$ of Theorem 1.

It follows from (53) and (54) when $L \varphi_{1}=L \varphi_{2}=0$ with $\Phi=\{0\}, R=[0, T)$, $S=S\left(t_{0}\right)=\left[0, t_{0}\right)$ for $t_{0} \in[0, T)$ that solutions to (7) are Hölder stable in the sense of F. John [5]. The technical identifications have been carried out in [9, pp. 95, 96]. They follow quite readily from the fact that under $\mathrm{C}-2$, for any $t_{0} \in[0, T), \gamma_{1}, \gamma_{2} \geqq 0$ and $w \in C^{0}\left(\left[0, t_{0}\right) ; D\right)$,

$$
\|w\|_{t_{0}} \equiv\left\{\int_{0}^{t_{0}}(w, M w) d s+\gamma_{1}(w, M w)_{0}+\gamma_{2}\|N w\|_{0}^{2}\right\}^{1 / 2}
$$

is a norm on $C^{0}\left(\left[0, t_{0}\right) ; D\right)$.

IV. Examples. In this section we mention briefly a few initial boundary value problems to which these results and the results of [10] can be applied. Throughout this section $B$ will denote a bounded region in $R^{m}$ (real Euclidian $m$ space), $H=L^{2}(\bar{B})$ and $\boldsymbol{x}=\left(x_{1}, \ldots, x_{m}\right) \in R^{m}$. The boundary, $\partial B$, of $B$ is assumed smooth enough to permit applications of Stoke's Theorem. The outward normal to $\partial B$ is denoted by $n=\left(n_{1}, \ldots, n_{m}\right)$. We shall also write $\partial B=S_{1} \cup S_{2}$ where $S_{1} \cap S_{2}=\varnothing$ and $S_{1}$ and $S_{2}$ are smooth or piecewise smooth submanifolds of $\partial B$. Summation over repeated Latin indices is to be understood. In order to prevent unnecessary confusion we shall denote by $u_{, i}$ the derivative $\partial u / \partial x_{i}$. Thus for example $a_{i, j}$ $=\partial a_{i} / \partial x_{j}$ while $a_{i j}$ is the $i j$ th entry of a matrix.

As our first example consider the equation

$$
u,_{t}+\left[a_{i j}(x, t) u,_{i t}\right]_{, j}=\left[b_{i j}(x, t) u_{i}\right]_{, j}+f(x, t, u)+\int_{0}^{t} g(x, t, \tau, u) d \tau
$$

in $B \times[0, T)$. The functions $f$ and $g$ are assumed to be continuous in their first two and three arguments respectively and uniformly Lipschitz in their last argument. 
We assume

(i) $a_{i j}=\mu b_{i j}$ on $S_{2} \times[0, T)$ for some constant $\mu \neq 0$.

(ii) $a_{i j} \xi_{i} \xi_{j} \leqq 0, \forall(x, t) \in B \times[0, T)$ and $\xi \in R^{m}$.

(iii) $\exists$ constants $\delta, \gamma$ with $\gamma \geqq 0 \ni\left(b_{i j, t}-\delta b_{i j}+\gamma a_{i j}\right) \xi_{i} \xi_{j} \leqq 0, \forall(x, t) \in B \times[0, T)$ and $\xi \in R^{m}$.

(iv) The matrices $\left(a_{i j}\right),\left(b_{i j}\right)$ are symmetric throughout $\bar{B} \times[0, T)$.

For initial and boundary conditions, we take

I.C. $u(x, 0)$ prescribed on $B$,

B.C. $u \equiv 0$ on $S \times[0, T), \quad a_{i j} n_{j} u_{,_{i}}\left(=\mu b_{i j} n_{j} u_{, i}\right)=0$ on $S_{2} \times[0, T)$.

It then follows from Theorem 2 and its first corollary that this problem has at most one solution (even with nonhomogeneous boundary data) and that the solution is stable in the sense of F. John [5] with respect to the initial data.

In [3], the authors considered a special case of this equation, namely, for $\Delta=\partial^{2} / \partial x^{2}+\partial^{2} / \partial y^{2}+\partial^{2} / \partial z^{2}$,

$$
c u,{ }_{t}+k \Delta u=c a \Delta u,_{t}+r(\boldsymbol{x}, t) .
$$

Here $k, c$ and $a$ are constants, $c \neq 0$ and $r$ is a given function. If $c$ and $c a$ have opposite signs then we may simply further specialize the example to this case. If, however, $c$ and $c a$ have the same sign, as for instance in the equation $u_{t}+u,_{x x t}=u,_{x x}$ which was considered in [4], then we must modify the example above to the following extent: We assume that

(i) $\left(a_{i j}\right)$ is independent of $t$ (for simplicity).

(ii) $\exists \lambda>0$ such that, $\forall(x, t) \in \bar{B} \times[0, T), \xi \in R^{m}, b_{i j} \xi_{i} \xi_{j} \geqq \lambda \xi_{i} \xi_{i}$.

(iii) $f$ and $g$ are independent of $u$.

(iv) $a_{i j}=\mu b_{i j}$ on $S_{2} \times[0, T)$ for some constant $\mu \neq 0$.

(v) The entries of $\left(b_{i j, t}\right)$ are uniformly bounded.

Then the initial boundary value problem for the above equation as prescribed above has at most one solution by part A of Theorem 1.

If instead of (iii) in the first set of assumptions above, we assume that there is a constant $\lambda<0$ such that $a_{i j} \xi_{i} \xi_{j} \leqq \lambda \xi_{i} \xi_{i}$ for all $(x, t) \in \bar{B} \times[0, T)$ and $\xi \in R^{m}$ then we can allow $f$ and $g$ to be jointly Lipschitz in both $u$ and $\operatorname{grad} u$. We can allow $\left(a_{i j}\right)$ to depend upon $t$ in this case if we have $\left(a_{i j, t}\right)$ uniformly bounded in $B \times[0, T)$. Moreover, if $a_{i j} \equiv 0$ then it is not necessary to assume that (i) in the first set of hypotheses holds. We can then take for our boundary conditions

$$
u \text { prescribed on } S_{1} \times[0, T), \quad n_{j} b_{i j} u,{ }_{j} \text { prescribed on } S_{2} \times[0, T) .
$$

Thus we are able to dispense simultaneously with the question of uniqueness for both the forward and backward heat equations with mixed boundary conditions.

As another example consider the equation

$$
-\Delta u,_{t}=\mu \Delta^{2} u+f(x, t, u, \nabla u)+\int_{0}^{t} g(x, t, \tau, u, \nabla u) d \tau
$$


in $B \times[0, T)$ for some constant $\mu$. Then we see that if $f$ and $g$ are jointly uniformly Lipschitz in their last two arguments, the following initial boundary value problem for this equation has at most one solution:

I.C. $u(x, 0)$ prescribed on $B$,

B.C. $u, \partial u / \partial n\left(=n_{i} u, i\right)$ prescribed on $\partial B \times[0, T)$.

(In all of the preceding examples necessary boundedness conditions on the coefficients in the equations as well as on the derivatives of the coefficients are assumed. Only the "essential" conditions are given.)

We include here some examples from the literature to which the result of [9] and [10] concerning (1) and (2) can be applied. Although these examples more appropriately should have been included in [10], we include them here in order to prevent that paper from becoming excessively long.

In [10] the equation

$$
\begin{aligned}
P(x, t) u_{t t}+\left(a_{i j}(x, t) u_{i t t}\right)_{, j}= & \left(b_{i j}(x, t) u_{, i}\right)_{, j}+f\left(x, t, u, u, t, \nabla u, \nabla u,_{t}\right) \\
& +\int_{0} g(x, t, \tau, \ldots) d \tau
\end{aligned}
$$

in $B \times[0, T)$ together with the conditions

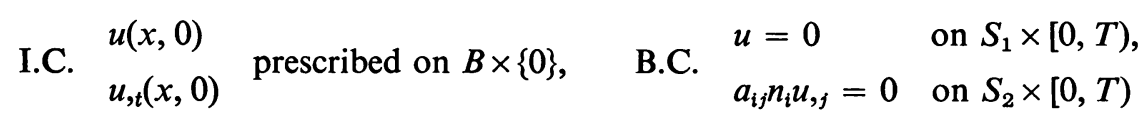

were discussed. The matrices $\left(a_{i j}\right)$ and $\left(b_{i j}\right)$ were assumed to be Hermitian $\left(A=\bar{A}^{t}\right)$ and such that $\left(a_{i j}\right)=\left(b_{i j}\right)$ on $S_{2} \times[0, T)$. The essential conditions on the matrices in order that there be at most one solution to the above initial boundary value problem were

(i) $\exists \lambda>0$ such that, $\forall(x, t) \in \bar{B} \times[0, T), \xi \in R^{m},-a_{i j} \xi_{i} \xi_{j} \geqq \lambda \xi_{i} \xi_{i}$,

(ii) $\exists$ constants $\delta, \gamma$ with $\gamma \geqq 0$ such that the matrix $\left(b_{i j, t}-\delta b_{i j}-\gamma a_{i j}\right)$ is negative semidefinite in $\bar{B} \times[0, T)$.

It was also necessary in [10] to assume that there was a constant $\lambda_{1}>0$ such that $P(x, t) \geqq \lambda_{1}$ in $\bar{B} \times[0, T)$, that $\partial P / \partial t$ was uniformly bounded, and that $f$ and $g$ were uniformly Lipschitz in their last four arguments. In the special case for which $\left(a_{i j}\right) \equiv 0$ it is not necessary to assume $\left(b_{i j}\right)=0$ on $S_{2} \times[0, T)$. However then the dependence of $f$ and $g$ upon their last two arguments must be dropped. A special case of this example, namely

$$
u_{t t}=\left(b_{i j} u,_{i}\right), j+f\left(x, t, u, u,,_{y}\right)
$$

with $S_{2}=\varnothing$ was considered in [14]. Earlier in [13], a further specialization, the Chaplygin equation, $u_{,_{y y}}+h(y) u_{x x}=0$ was discussed. In [14] another application of these results, namely the initial boundary problem for the wave equation $\left(u_{, y y}=u,_{t t}-u_{x x}\right)$ in a space like direction was mentioned. As another example we 
include the initial boundary value problem for the equation

$$
u,_{t t}=u,_{x x}+u,_{y y}-u,_{z z},
$$

which is the simplest example of equations of the so called "ultra hyperbolic" type.

As a final example let us consider the vector equation

$$
\rho(\boldsymbol{x}) \boldsymbol{u}_{t t}=\left(A_{j l} \boldsymbol{u}_{l,}\right)_{, j}
$$

where $u: B \times[0, T) \rightarrow R^{k}$ and the $A_{j l}$ 's are $m^{2}$ real $k \times k$ matrices depending only upon $\boldsymbol{x} \in B$ satisfying $A_{j l}=A_{l j}^{T}, j, l=1,2, \ldots, m$. Here $p(x)$ is a function bounded below by a positive constant $\left({ }^{3}\right)$. The appropriate initial boundary value problem for this system is

$$
\begin{array}{llll}
\text { I.C. } \begin{array}{l}
u(x, 0) \\
u_{, t}(x, 0)
\end{array} \quad \text { prescribed on } B, & \text { B.C. } \begin{array}{l}
u=0 \\
n_{j} A_{j l} u_{, l}=\mathbf{0}
\end{array} & \text { on } S_{2} \times[0, T) .
\end{array}
$$

For our Hilbert space $H$ we take $H=L^{2}(B) \times L^{2}(B) \times \cdots \times L^{2}(B)(k$ factors) and for our inner product $(\boldsymbol{u}, \boldsymbol{v}) \equiv \sum_{i=1}^{k} \int_{B} u_{i} v_{i} d x$. Now the uniqueness and stability theorems of [10] apply directly to this problem since we have that $M=\rho(x) I$, $M^{\prime}=0, N=\left(\partial / \partial x_{j}\right)\left(A_{j l}(x) \partial / \partial x_{l}\right)$ and $N^{\prime}=0\left(^{\prime}=d / d t\right)$. If we take $m=k=3$ then this system reduces to the system of equations of linear elasticity which were discussed in [7] and [8]. The results of [10] can be directly applied to this system to deduce the results of [7] and [8].

Acknowledgement. The author wishes to thank Professor L. E. Payne of the Department of Mathematics, Cornell University for his generous advice and helpful suggestions.

Added in proof. Theorem 1, part D can be reduced to Theorem 1, part $\mathrm{E}$ in the special case for which $M^{\prime}=0$ and $P=M^{-1 / 2}$ exists. Since $M$ is symmetric so is $M^{-1}$ and thus $P$ is as well. The change of variables $v=P^{-1} u$ reduces the equation $M u_{t}=N_{1} u+N_{2} u+N_{3} u+f(t, u)$ to $v_{t}=\tilde{N}_{1} v+\tilde{N}_{2} v+\tilde{N}_{3} v+P f(t, P v)$ where $\tilde{N}_{i}=P N_{i} P$, $i=1,2,3$. For some $\lambda>0(x, M(t) x) \geqq \lambda(x, x)$ for all $x \in D$ and hence $M^{-1}$ and $P$ are bounded operators. Therefore there exist constants $k_{1}$ and $k_{2}$ such that

$$
\|P f(t, P(u-v))\|^{2} \leqq k_{1}\|u-v\|^{2}+k_{2} \int_{0}^{t}\|u-v\|^{2} d s
$$

Moreover

$$
\begin{aligned}
\left|\left(P x, N_{1} P x\right)\right| & \leqq\left|\left(x, \tilde{N}_{1} x\right)\right|+\|P\|\left\|^{2}\right\| x \|^{2} \\
& \leqq \max \left(1,\|P\|^{2}\right)\left(\left\|\tilde{N}_{1} x\right\|\|x\|+\|x\|^{2}\right) .
\end{aligned}
$$

Thus since $\left\|\tilde{N}_{3} x\right\|^{2} \leqq\|P\|^{2}\left\|N_{3} P x\right\|^{2}, \quad \operatorname{Re}\left(\tilde{N}_{1} x, \tilde{N}_{2} x\right)=\operatorname{Re}\left(M^{-1} N_{1} P x, N_{2} P x\right)$,

$\left(^{3}\right.$ Actually, in the linear problem here, it is enough to assume that $\rho(x)>0$ in $B$ as remarked in [10]. If $\rho(x) \geqq \lambda>0$, then nonlinear terms may be added of the form $f(x, t, u, u, t)$ where $f$ is Lipschitz in its last two arguments jointly. 
$P^{\prime}=0$ and $\left(x, \tilde{N}_{1}^{\prime} x\right)=\left(P x, N_{1}^{\prime} P x\right)$, we can deduce E-4 from D-6. However, when $M$ depends upon $t$ all sorts of problems arise. For example, the existence of $M^{\prime}$ may not imply the existence of $P^{\prime}$. Even when $P^{\prime}$ does exist we have $\tilde{N}^{\prime}=P^{\prime} N_{1} P+P N_{1} P^{\prime}$ $+P N_{1}^{\prime} P$ and we find ourselves faced with the difficult task of proving that there exist nonnegative constants $k_{1}, k_{2}$ such that

$$
\max \left\{-\left(x, P^{\prime} N_{1} P x\right),-\left(x, P N_{1} P^{\prime} x\right)\right\} \leqq k_{1}\|x\|\left\|\tilde{N}_{1} x\right\|+k_{2}\|x\|^{2} .
$$

All we have to work with in order to prove this are the inequalities

$$
(x, M x) \geqq \lambda(x, x) \quad(\lambda>0)
$$

and

$$
\left|\left(x, M^{\prime} y\right)\right|^{2} \leqq \mu(x, M x)(y, M y)
$$

together with the equations

$$
\left(M^{-1}\right)^{\prime}=-M^{-1} M^{\prime} M^{-1}
$$

and

$$
\left(M^{-1}\right)^{\prime}=P P^{\prime}+P^{\prime} P
$$

where $P=M^{-1 / 2}$.

\section{BIBLIOGRAPHY}

1. S. Agmon, Unicité et convexité dans les problèmes différentiels, Sem. Math. Sup. (1965), Univ. of Montreal Press, 1966.

2. S. Agmon and L. Nirenberg, Lower bounds and uniqueness theorems for solutions of differential equations in a Hilbert space, Comm. Pure Appl. Math. 20 (1967), 207-229. MR 34 \#4665.

3. P. J. Chen and M. E. Gurtin, On a theory of heat conduction involving two temperatures, Z. Angew. Math. Phys. 19 (1968), 614-627.

4. B. D. Coleman, R. J. Duffin and V. J. Mizel, Instability, uniqueness, and nonexistence theorems for the equation $u_{t}=u_{x x}-u_{x t x}$ on a strip, Arch. Rational Mech. Anal. 19 (1965), 100-116. MR 31 \#1479.

5. F. John, Continuous dependence on data for solutions of partial differential equations with a prescribed bound, Comm. Pure Appl. Math. 13 (1960), 551-585. MR 24 \#A317.

6. R. J. Knops and L. E. Payne, On the stability of solutions to the Navier-Stokes equations backward in time, Arch. Rational Mech. Anal. 29 (1968), 331-335. MR 37 \#1812.

7. - Stability in linear elasticity, Internat. J. Solid Structures 4 (1968), 1233-1242.

8. - Uniqueness in classical elastodynamics, Arch. Rational Mech. Anal. 27 (1968), 349-355. MR 36 \#2344.

9. H. A. Levine, Convexity and differential inequalities in Hilbert space, Ph.D. Dissertation, Cornell University, Ithaca, N. Y., 1969.

10. - Logarithmic convexity and the Cauchy problem for some abstract second order differential inequalities, J. Differential Equations 8 (1970), 34-55

11. L. E. Payne, Bounds in the Cauchy problem for the Laplace equation, Arch. Rational Mech. Anal. 5 (1960), 35-45. MR 22 \#1743.

12. - On some non well posed problems for partial differential equations, Proc. Adv. Sympos. Numerical Solutions of Nonlinear Differential Equations (Madison, Wis., 1966), Wiley, New York, 1966, pp. 239-263. MR 35 \#4606. 
13. L. E. Payne and D. Sather, On some improperly posed problems for the Chaplygin equation, J. Math. Anal. Appl. 19 (1967), 67-77. MR 35 \#3278.

14. - On some improperly posed problems for quasilinear equations of mixed type, Trans. Amer. Math. Soc. 128 (1967), 135-141. MR 35 \#3279.

15. T. I. Zelenjak, Asymptotic solution of a mixed problem, Differencial'nye Uravnenija 2 (1966), 47-64 = Differential Equations 2 (1966), 23-32. MR 33 \#444.

16. R. Carroll, Some growth and convexity theorems for second order equations, J. Math. Anal. Appl. 17 (1967), 508-518. MR 35 \#510.

Forschungsinstitut für Mathematik, Eidgenössische Technische Hochschule, ZÜRICH, SWITZERLAND 